\title{
A case of OXA-48 carbapenemase-producing Klebsiella pneumoniae in a patient transferred to Slovenia from Libya, November 2011
}

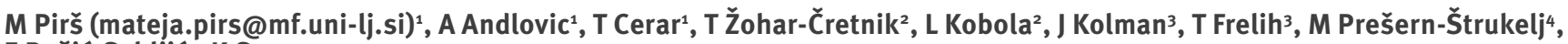
E Ružić-Sabljićc ${ }^{1}$, K Seme ${ }^{1}$

1. Institute of Microbiology and Immunology, Faculty of Medicine, Ljubljana, Slovenia

2. Institute of Public Health, Celje, Slovenia

3. National Institute of Public Health, Ljubljana, Slovenia

4. University Rehabilitation Institute, Ljubljana, Slovenia

Citation style for this article:

Pirš M, Andlovic A, Cerar T, Žohar-Čretnik T, Kobola L, Kolman J, Frelih T, Prešern-Štrukelj M, Ružić-Sabljić E, Seme K. A case of OXA-48 carbapenemase-producing Klebsiella pneumoniae in a patient transferred to Slovenia from Libya, November 2011.

Euro Surveill. 2011;16(50):pii=20042. Available online: http://www.eurosurveillance.org/ViewArticle.aspx?Articleld=20042

We report the first documented case of OXA-48producing Klebsiella pneumoniae in Slovenia isolated from rectal surveillance cultures from a patient transferred from Libya. The patient was colonised with both ESBL-producing Escherichia coli and ESBL- and OXA48-producing $K$. pneumoniae. Three further patients were colonised with ESBL-producing $E$. coli. This underscores the importance of an early warning system on European level and screening upon admission of patients transferred across borders and between healthcare systems.

In the beginning of November 2011, 25 patients from Libya were admitted to two rehabilitation facilities in Slovenia, 22 of whom were otherwise healthy amputees. None were transferred directly from a hospital; more detailed information regarding previous hospitalisation was not available. A rapid risk assessment circulated by the European Centre for Disease Prevention and Control (ECDC) on 31 October 2011 states that provision of healthcare to patients transferred from Libya to the European Union is likely to present a high risk of introduction of multidrug-resistant bacteria [1]. Therefore, the Slovenian National Institute of Public Health (NIPH) issued a warning and recommended rectal screening of all transferred Libyan patients for the presence of multidrug-resistant Gram-negative bacteria. The rapid risk assessment as well as another ECDC risk assessment on carbapenemase-producing Enterobacteriaceae [2] was distributed to the relevant institutions accepting Libyan patients and to relevant microbiological laboratories. Screening of all hospitalised patients from foreign countries, and patients transferred from hospitals and nursing homes is also part of the Slovenian national guidelines for screening for extended-spectrum beta-lactamase (ESBL)-producing and carbapenemase-producing Enterobacteriaceae [3].

\section{Microbiological screening \\ Methods}

Rectal swabs were collected upon admission from all 25 patients and screened for the presence of ESBL- and/ or carbapenemase-producing Enterobacteriaceae and carbapenem-resistant Acinetobacter baumannii and Pseudomonas aeruginosa. Samples from 14 patients were processed at the Institute of Microbiology and Immunology, Faculty of Medicine Ljubljana and the remaining 11 at the Institute of Public Health Celje.

Samples were vortexed in tryptic soy broth (TSB), aliquots were inoculated onto ChromID ESBL agar (bioMerieux, France), MacConkey (MAC) agar onto which $10 \mu \mathrm{g}$ carbapenem discs were placed, and TSB. Following 24-hour incubation, TSB was subcultured onto MAC agar onto which $10 \mu \mathrm{g}$ carbapenem discs were placed [4-7]. Reduced susceptibility to carbapenems was suspected in any colony growing within the $23 \mathrm{~mm}$ inhibition zone for Enterobacteriaceae or the $16 \mathrm{~mm}$ inhibition zone for non-fermentative Gramnegative bacilli. Antimicrobial susceptibility testing was performed according to guidelines of the Clinical Laboratory Standards Institute (CLSI) [8]. Phenotypic tests for the detection of carbapenemases, inhibition tests using boronic or dipicolinic acid and ethylenediaminetetraacetic acid (EDTA) as well as a modified Hodge test (MHT) were performed as per the CLSI and Giske et al. [8,9]. Molecular detection of blaOXA-48 was done by polymerase chain reaction (PCR) [10].

\section{Results}

Four of the 25 patients were colonised with ESBLproducing Escherichia coli, detected on solid media. In one of these colonised patients an ESBL-producing and carbapenem-resistant $K$. pneumoniae isolate was also isolated, however only after the enrichment step. Phenotypic tests for detection of carbapenemases were 
performed on this strain and there was no inhibition by boronic, dipicolinic acid or EDTA. PCR for blaOXA-48 was positive. Laboratory contamination was ruled out as this is the first OXA-48 carbapenemase isolate in the laboratory and the resistance profile of this and the reference strain are completely different.

The OXA-48-producing K. pneumoniae isolate was susceptible to amikacin (minimal inhibitory concentration (MIC): $4 \mu \mathrm{g} / \mathrm{mL}$ ), trimethoprim/sulfamethoxazole (MIC: $1 \mu \mathrm{g} / \mathrm{mL}$ ) and colistin (MIC: $0.25 \mu \mathrm{g} / \mathrm{mL}$ ) but resistant to all beta-lactams including carbapenems (MIC for cefotaxime, imipenem, meropenem and ertapenem were $\geq 32 \mu \mathrm{g} / \mathrm{mL}$, MIC for piperacillin/tazobactam was $\geq 256 \mu \mathrm{g} / \mathrm{mL}$ ), ciprofloxacin (MIC: $32 \mu \mathrm{g} / \mathrm{mL}$ ) and tigecycline (MIC: $2 \mu \mathrm{g} / \mathrm{mL}$; tigecycline MIC was interpreted according to criteria of the European Committee on Antimicrobial Susceptibility Testing (EUCAST) [11]).

No carbapenem-resistant $A$. baumannii or P. aeruginosa were isolated.

\section{Control measures}

On admission, the patients were placed in a dedicated ward. Separate scheduling of treatment (last on the daily schedule) and disinfection of shared equipment were implemented during rehabilitation therapy. Following the warning from the NIPH the patients were additionally placed in contact isolation.

After isolation of multidrug-resistant Gram-negative bacteria, the colonised patients were cohorted, and the patient colonised with both ESBL-producing E. coli and ESBL- and OXA-48-producing $K$. pneumoniae was placed in a single room. The patients and staff were further educated and encouraged to perform increased hand hygiene and frequent hand disinfections. Special precautions such as separate scheduling of treatment (last on the schedule) and disinfection of shared equipment were continued for all patients until their discharge after approximately one month.

\section{Discussion and conclusion}

This is the first documented case of OXA-48-producing $K$. pneumoniae in Slovenia. The patient was colonised with both ESBL-producing E. coli and ESBL- and OXA48-producing $K$. pneumoniae. Three further patients were colonised with ESBL-producing $E$. coli. The four cases clearly demonstrate the usefulness of alert systems on the European level where countries can share their experiences and translate them into public health action. Had the warning not been issued, the patients would not have been screened for the presence of carbapenemase-producing Gram-negative bacteria.

In addition, the carbapenemase-producing K. pneumoniae was only detected following the enrichment step, which may indicate a low-level colonisation with carbapenemase-producing $K$. pneumoniae and predominance of ESBL-producing $E$. coli which probably overgrew $K$. pneumoniae on ESBL agar. These results demonstrate the usefulness of an enrichment step as part of screening for carbapenemase-producing Enterobacteriaceae.

We hope that by the early warning from NIPH, the isolation of the patients that were transferred to Slovenia from Libya and the early detection of OXA-48-producing K. pneumoniae, the introduction of a novel carbapenemase into Slovenia was successfully contained.

\section{References}

1. European Centre for Disease Prevention and Control (ECDC). Rapid risk assessment. Transfer of Libyan patients to hospitals in the European Union. Stockholm: ECDC; 31 Oct 2011.

2. European Centre for Disease Prevention and Control (ECDC). Risk assessment on the spread of carbapenemase-producing Enterobacteriaceae (CPE) through patient transfer between healthcare facilities, with special emphasis on cross-border transfer, Stockholm: ECDC; 13 Sep 2011. Available from: http:// ecdc.europa.eu/en/publications/Publications/Forms/ECDC DispForm.aspx?ID =740

3. Nacionalna komisija za obvladovanje bolnišničnih okužb (NAKOBO). [National committee for infection control and prevention]. Priporočila za preprečevanje širjenja ESBL pozitivnih bakterij in karbapenemaza pozitivnih bakterij. [Guidelines for the prevention of transmission of ESBL- and carbapenemase-producing bacteria]. Ljubliana; Ministry of Health; 2010. [Accessed 1 Dec 2011]. Slovenian. Available from: http://www.mz.gov.si/fileadmin/mz.gov.si/pageuploads/ $\mathrm{mz}$ _dokumenti/delovna_podrocja/zdravstveno_varstvo/ zdravstveno_varstvo_v_posebnih/NAKOBO_oktober_2010/ PRIPOROCILA_ESBL_26.10.10.pdf

4. Landman D, Salvani JK, Bratu S, Quale J. Evaluation of techniques for detection of carbapenem-resistant Klebsiella pneumoniae in stool surveillance cultures. J Clin Microbiol. 2005;43(11):5639-41.

5. Lolans K, Calvert K, Won S, Clark J, Hayden MK. Direct ertapenem disk screening method for identification of KPC-producing Klebsiella pneumoniae and Escherichia coli in surveillance swab specimens. J Clin Microbiol. 2010;48(3):836-41.

6. Calfee D, Jenkins SG. Use of active surveillance cultures to detect asymptomatic colonization with carbapenem-resistant Klebsiella pneumoniae in intensive care unit patients. Infect Control Hosp Epidemiol. 2008;29(10):966-8.

7. Centers for Disease Control and Prevention (CDC). Laboratory protocol for detection of carbapenem-resistant or carbapenemase-producing, Klebsiella spp. and E. coli from rectal swabs. Atlanta: CDC. [Accessed 1 Dec 2011]. Available from: http://www.cdc.gov/HAl/pdfs/labSettings/Klebsiella or_Ecoli.pdf

8. Clinical Laboratory Standards Institute (CLSI). Performance standards for antimicrobial susceptibility testing; twenty-first informational supplement. M100-S21. Vol 31 No. 1. Wayne: CLSI; Jan 2011. Available from: http://www.clsi.org/source/ orders/free/m100-s21.pdf

9. Giske CG, Gezelius L, Samuelsen O, Warner M, Sundsfjord A, Woodford N. A sensitive and specific phenotypic assay for detection of metallo-beta-lactamases and KPC in Klebsiella pneumoniae using meropenem discs supplied with boronic acid, dipicolinic acid and cloxacillin. Clin Microbiol Infect. 2011;17(4):552-6.

10. Poirel L, Héritier C, Tolün V, Nordmann P. Emergence of oxacillinase-mediated resistance to imipenem in Klebsiella pneumoniae. Antimicrob Agents Chemother. 2004;48(1):15-22.

11. European Committee on Antimicrobial Susceptibility Testing (EUCAST). Breakpoint tables for interpretation of MICs and zone diameters. Version 1.3. EUCAST; 5 Jan 2011. [Accessed 1 Dec 2011]. Available from: http://www.eucast.org/fileadmin/ src/media/PDFs/EUCAST_files/Disk_test_documents/EUCAST_ breakpoints_v1.3_pdf.pdf 